\title{
OPEN COLECTOMY UNDER EPIDURAL ANESTHESIA ONLY: A CASE REPORT
}

\author{
Georgios Karpetas $^{1}$, Maria Spyraki ${ }^{1}$, Athina Siampalioti ${ }^{1}$, Eleni Sintou ${ }^{1}$,George Skroubis² \\ ${ }^{1}$ Anesthesiologist, Critical Care and Anesthesia Department, University Hospital of Patras, Patras, Greece \\ ${ }^{2}$ Associate Professor of Surgery, Department of Surgery, University Hospital of Patras, Patras, Greece
}

\section{Background and aims}

While the elderly population continues to increase, more octogenarians require surgery. Anesthesia management becomes more challenging for the elderly since the prevalence of comorbid diseases is higher. We present a case report of an 84 year old woman, with severe COPD, undergoing left colectomy under single epidural anesthesia. Our aim is to demonstrate the efficacy of epidural anesthesia in patients, on high risk for cardio-pulmonary complications, undergoing abdominal surgery.

\section{Methods}

An 84 year old Caucasian woman, ASA III, was admitted to our hospital due to almost complete large bowel obstruction, due to recurrent episodes of large bowel ischemia. Her clinical history included heart failure, atrial fibrillation, diabetes mellitus, bronchial asthma under oxygen therapy ( $F E V 1=53 \%$, $\mathrm{PEF}=52 \%, \mathrm{pO} 2=62 \mathrm{mmHg}$ on room air) and myelodysplastic syndrome. Due to her comorbidities, she was planned for open left colectomy under single epidural anesthesia. After locating the thoracic epidural space at level T8-T9 an epidural catheter was introduced. A test dose of $3 \mathrm{ml}$ lidocaine $2 \%$ was injected, while the anesthesia was maintained with $5 \mathrm{ml}$ ropivacaine $0.75 \%$ at the beginning following with a $5 \mathrm{ml}$ bolus ropivacaine $0.375 \% 40$ minutes after the initial dose.

\section{Results}

The patient underwent open left colectomy with laterolateral anastomosis (transverse to sigmoid colon). The operation lasted 2 hours. During the surgery the patient remained hemodynamically stable, vasopressors was not used while the anesthesia level was optimal. No pulmonary burden was observed. Additionally, the epidural catheter was used for postoperative analgesia. Postoperative course was uneventful and the patient was discharged six days later. None complication observed for 30 days postoperatively.

\section{Conclusions}

Single epidural anesthesia for abdominal surgery remains a challenge for the anesthesiologist. However high risk patients, including octogenarians, benefit from epidural anesthesia for such operations, a fact that contributes to reduced morbidity and mortality.

\section{References}

1. Effective awake thoracic epidural anesthetic for major abdominal surgery in two high-risk patients with severe pulmonary disease--a case report, Abd Elrazek E, Thornton M, Lannigan A. Middle East J Anaesthesiol. 2010 Oct;20(6):891-5.

2. Thoracic epidural anesthesia for open cholecystectomy in severe lung disease. Description of a case and review of the literature, Gonzalez-Mendibil I, Postigo-Morales S, Gonzalez-Larrabe I, Arizaga-Maguregi A. Rev Esp Anestesiol Reanim. 2015 Dec;62(10):576-9.

3. A Case of Resection of Obstructive Colon Cancer Associated with Aspiration Pneumonia, Under Combined Epidural-Spinal Anesthesia, Hayashi K, Murata K, Naito A, Kagawa Y, Kawai K, Mori R, Nose Y, Akiyama Y, Sakamoto T, Murakami K, Masuzawa T, Katsura Y, Ohmura Y, Takeno A, Takeda Y. Gan To Kagaku Ryoho. 2017 Nov;44(12):1970-1972.
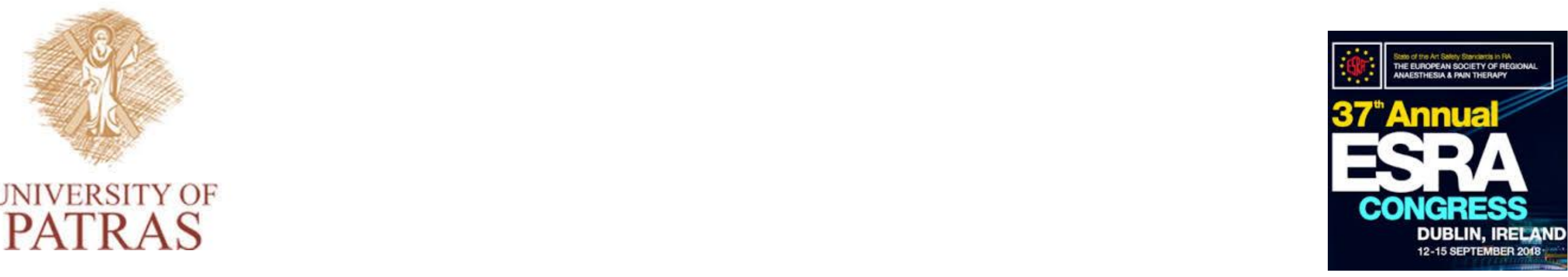